EDITORIAL

\title{
Are we there yet?
}

(c) The Author(s), under exclusive licence to Springer Nature Limited 2022

Bone Marrow Transplantation (2022) 57:697-698; https://doi.org/ 10.1038/s41409-022-01624-7

True happiness is to enjoy the present, without anxious dependence upon the future, not to amuse ourselves with either hopes or fears but to rest satisfied with what we have, which is sufficient, for he that so wants nothing.

Seneca. Roman Stoic Philosopher. (4 BC - 65 AD). Fig. 1.

Although the use of blood and blood products has decreased due to more judicious use and the establishment of 'transfusion comities', the clamour for more chemotherapy, requiring haemopoietic cell support red blood cell concentrates and platelets, and more complicated surgery, also requiring haemopoietic support, the number of volunteer blood donors in the developed world continues to be stubbornly stuck at around 5\%. There is no doubt that the recent SARS-CoV-2 pandemic has put an added strain on blood transfusion services. The public received mixed signals; stay at home unless absolutely necessary: please attend blood donation clinics [personal communication, Irish blood transfusion service]. An appointment system was introduced by a number of donation clinics, which helped to alleviate shortages.

Is there another way to make sure red blood cells are available in difficult times? Yes. Cryopreservation of Red Blood Cells has been a well-established technique for some time in many blood banks to make erythrocytes available to people with multiple red cell allo-anti-bodies such as some patients with sickle cell disease (SCD) [1] and people with rare blood groups.

Another approach is the attempt to grow red blood cells from erythroid progenitors. It is relatively easy to culture small amounts of red blood cell progenitors (BFU-E and CFU-E) but expanding them is a different question. One advantage if they could be used for transfusion might be to avoid iron overload from repeated blood transfusion [2]. As yet the provision of such a product eludes clinical use.

A totally different approach is to increase the supply of oxygen carrying capacity i.e. Hgb solutions. Potentially the use of these might be life saving in major trauma or on the battle - field. Alayash A.l. has published a review (2020) of hemoglogin-based blood substitutes (HBOC) but nephrotoxicity and hypertension have precluded a license [3]. So, for the present we continue to rely on volunteer donors to supply oxygen-carrying capacity. Hopefully with further research HBOC will attain a place in clinical practice. In a recent conversation with John Holcomb, trauma surgeon and member of the advisory board of the Thebloodproject.com (TBP) he said: 'a solution waiting for a problem'. So, were not there yet!

The presence of so-called blood group antigens continues to be an impediment to universal blood transfusion. A number of researchers have been trying to strip blood group antigens while preserving the integrity and function of erythrocytes [4]. Unfortunately the research has not translated into a clinical reality yet. So, we're not there yet!

Can grapes be used for things other than making wine? Yes. Dried grape skins can be used to make the digestive 'Grappa'. A popular drink in Italy it sometimes comes in very special bottles Fig. 2. Grappa is strong but makes an excellent after dinner drink. There are specific rules about making grappa. 1. It must be produced in Italy, part of Switzerland, or San Marino. 2. It must be produced from pomace. 3. Fermentation and distillation must occur on the pomace-no added water. The bottle in the Fig. 2 was purchased in the rather poorly restored Abbey of Montecassino, which was heavily damaged during WWII.

One of the most intriguing developments is the use of grape skins and stalks to manufacture vegan leather products. Thalia Barrera writing in the website Tech Fashionista: Vegan leather made from grapes. Meet the Eco-Friendly Vegea. August 2021. Apparently Francisco Merlino, an environmental chemist with Gianpiero Tessitore, a furniture designer have developed Vegan

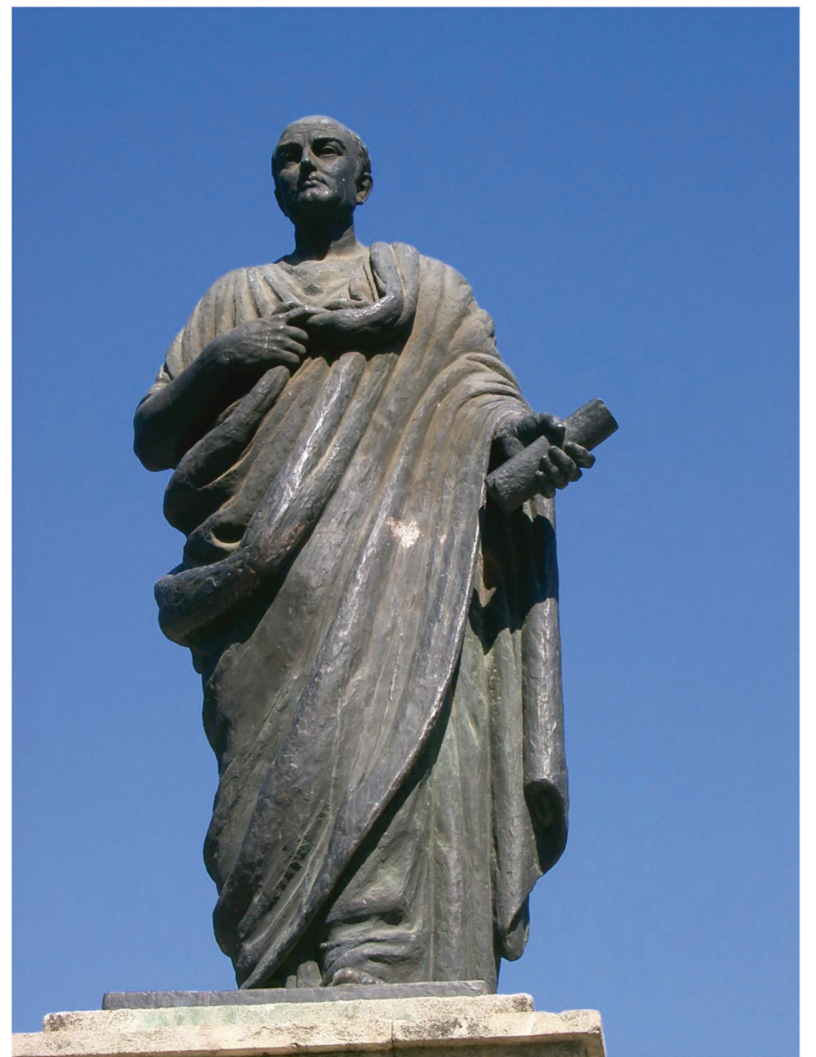

Fig. 1 Seneca. Statue of Seneca in Córdoba, Spain. Creative Commons Attribution-Share Alike 3.0 unported. 


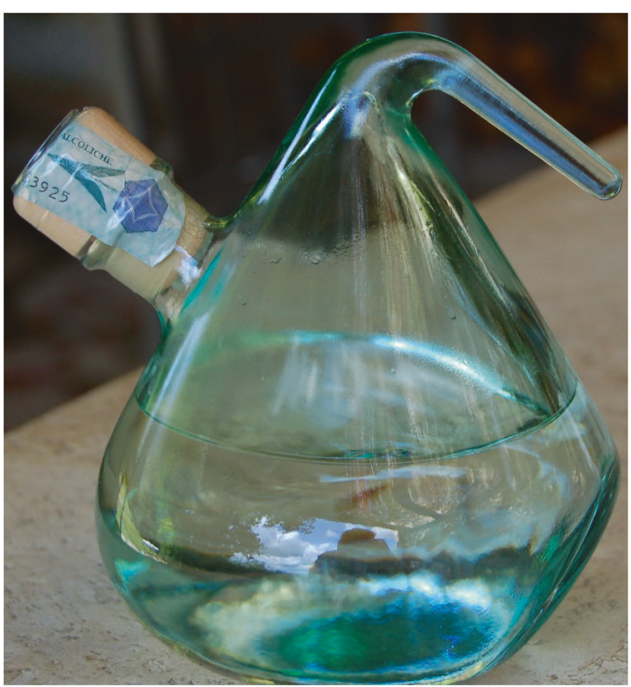

Fig. 2 Grappa. A bottle of grappa from Montecassino, Italy. Photograph by Shaun R McCann.

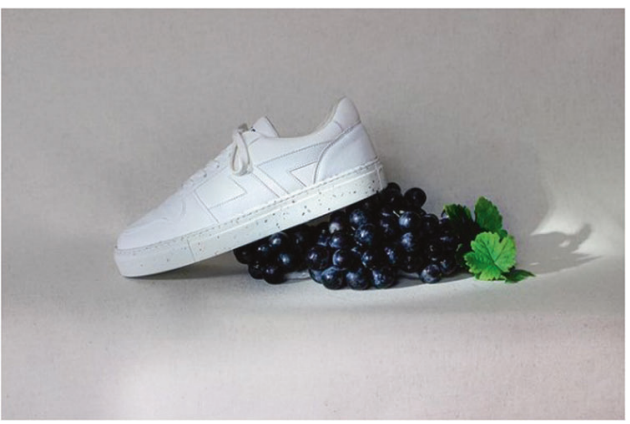

Fig. 3 Sneakers. Footwear made from dried grape skins. Copyright Zeta shoes instagram. 2022.

Leather from grape stalks Fig. 3. The problem is that water-based polyurethane (PUD) must be added which is difficult to biodegrade. Most of the products are foot-ware so if you like wearing Vegan sandles, watch this space. I was never a fan of sandals, especially with socks. So, I don't think I'll be a convert to vegan foot coverings.
I presume we will all worry about developing dementia, if we live long enough. The good news, however, is that it may be possible to avoid dementia. Weyer $S$ and colleagues [5] reported that light- to moderate alcohol is inversely related to incident dementia. I'll drink to that.

\section{Shaun R. McCann $\mathbb{D}^{1 凶}$ \\ ${ }^{1}$ Bone Marrow Transplantationhttps://www.nature.com/bmt. 凶email: shaunrmccann@gmail.com}

\section{REFERENCES}

1. Lagerberg JW. Cryopreservation of red blood cells. Methods Mol Biol. 2015. https:// doi.org/10.1007/978-1-4939-5-17.

2. Moore EE, Johnson JL, Cheng AM, Masuno T, Banerjee A. Insights from studies of blood substitutes in trauma. Shock. 2005;24:197-205. https://doi.org/10.1097/ 01shk.0000180075.76766.fe.

3. Evaluating the Safety and Efficacy of Hemoglobin-based blood substitutes. Alayash A.I. 2020. Office/Division/Lab: OBRR/DBCD/LBVB.

4. Abbon A. Blood made suitable for all. Nature. April 2007. https://doi.org/10.1038/ news $070326-17$

5. Weyer S, Schaufele M, Wiese B, Maier W, Tabrath F, van den Busche $H$, et al. Current alcohol consumption and its relationship to incident dementia: results from a 3-year follow-up study among attendees aged 75 years and older. Age Aging. 2011;40:463-9. https://doi.org/10.1093/aging1-5af054.

\section{AUTHOR CONTRIBUTIONS}

All the ideas and all the writing was done by Shaun R. McCann.

\section{COMPETING INTERESTS}

The author declares no competing interests.

\section{ADDITIONAL INFORMATION}

Correspondence and requests for materials should be addressed to Shaun R. McCann.

Reprints and permission information is available at http://www.nature.com/ reprints

Publisher's note Springer Nature remains neutral with regard to jurisdictional claims in published maps and institutional affiliations. 